\title{
Modelling of the Effect of Scale on the Compressibility Parameters of Fine- Grained Soils
}

\begin{abstract}
The effect of sample scale represents a challenge when obtaining engineering parameters in the laboratory compared to those obtained in the field. This study aimed at contributing to existing knowledge numerically using the finite element software PLAXIS 2D. The investigations were analysed in terms of height scale (HS) and diameter scale (DS) through a series a laboratory tests. Its effect on compressibility parameters such as coefficient of consolidation $\left(c_{v}\right)$ was noted experimentally and showed that sample scale greatly influences soil parameters most particularly at DS. The soil behaviour was found to be dependent on both DS and HS with a correlation factor of 0.650 and 0.062 respectively. The experimental data were validated in PLAXIS and a new proposed model was developed in PLAXIS 2D under the DS. The new proposed model developed was found to show no significant difference with the laboratory data.
\end{abstract}

Keywords: Compressibility, Fine-grained soils, PLAXIS 2D, Sample Scale

\section{Introduction}

The finite element method (FEM) has been widely used in the analysis of soil behaviour. Lenk (2009) conducted a series of one-dimensional consolidation tests using the Oedometer apparatus to investigate time-dependent settlement in high-rise buildings for fully saturated clay. The investigation consisted of validating the experimental findings with the FEM and ANSYS 3D was used to model a 4-node plane soil model with 13 elements. The effect of scale was not accounted for in Lenk's investigation but the consolidation test was conducted on samples with dimensions of $80 \mathrm{~mm}$ diameter and $30 \mathrm{~mm}$ thickness. Both the experimental data and the numerical modelling were found to correlate well. Popa and Batali (2010) presented a FEM for an embedded retaining wall and compared the results numerically and experimentally. The FEM was conducted using linear elastic, two nonlinear elastic-hardening models and a Mohr-Coulomb model. Each model was compared, and this revealed that the FEM can lead to false results due to model complexity and many parameters. It was also observed that the difference between the numerical and experimental results was reduced, and the Mohr- 
Coulomb model was less sensitive compared to the elasticity modulus. On the other hand, the hardening model showed a good correlation with the experimental data. PLAXIS 2D has been used by various researchers such as Aissa and Abdeldjalil (2013) and Wong (2013) in modelling soil behaviour. Aissa and Abdeldjalil (2013) modelled the behaviour of retaining walls stuck in the sand by subgrade reaction method. Both the experimental and numerical methods were compared and were found to correlate well. Wong (2013) modelled a single drainage line element under radial consolidation both with PLAXIS 2D and 3D and found that PLAXIS 3D yields comparably accurate results to $2 \mathrm{D}$.

Various investigations have been carried out by some researchers to study the effect of soil thickness on the compressibility parameters. Healy and Ramanjaneya (1970), Berry and Reid (1987), Ortega (1996) and Khan et al. (2012) carried out separate investigations into the relationship between soil thicknesses on the coefficient of consolidation $\left(\mathrm{c}_{\mathrm{v}}\right)$ and revealed that $c_{v}$ increases with an escalation in soil thickness. Sivrikaya and Togrol (2006) and Yin and Graham (1996) investigated the effect of sample thickness on strain-stress behaviour and found that the relationship between strain and effective stress at the end of primary consolidation (EOP) is not unique but depends on the thickness of the clay layer. Khan et al. (2012) investigation was on the effect of sample thickness on the degree of settlement, time factor and the degree of dissipation of pore water pressure with time. The investigation was carried using the finite difference method and the result was compared with that of conventional linear consolidation theory. The findings revealed that, the variation in the degree of settlement with time is relatively large whilst the variation in the pore pressure dissipation with time is relatively small for thick clays as compared to thin clay layers.

On the other hand, limited research has been completed on the effect of soil sample diameter on the compressibility parameters (coefficient of consolidation $\left(\mathrm{c}_{\mathrm{v}}\right)$, compression index $\left(c_{c}\right)$ and coefficient of volume compressibility $\left.\left(m_{v}\right)\right)$. Healy and Ramanjaneya (1970) 
looked at sample diameter effect on the value of $c_{v}$ using Varved clay. During the investigation, the value of $c_{v}$ was obtained using the Casagrande and pore water pressure method considering both vertical and horizontal (or radial) water flow within the soil sample. The value of $c_{v}$ obtained under radial flow was found to be independent of sample diameter (i.e. there was no significant difference in the value of $c_{v}$ with a change in soil diameter). Under vertical flow, the value of $c_{v}$ obtained was found to differ greatly than that achieved in the radial flow.

The current study provides an enhanced understanding of sample scale on the behaviour of fully saturated fine-grained soils with attention to the diameter scale. A series of laboratory tests on kaolin clay with an initial moisture content ranging from 55\% to $91 \%$ were modelled with PLAXIS. Within PLAXIS 2D, the Mohr-Coulomb (MC) model for the simulation as it is the most employed in the modelling of consolidation tests.

\section{Experimental study}

The sample preparation and test setup as described in the British and American standard (British Standard BS1377: part 2 (BS 1990) and American Standard D4318 (ASTM 2010)) were adopted. A well-known consolidation test was carried out using the Oedometer apparatus. A sample of kaolin clay (in powder form) was mixed with tap water using a soil mixer. The powder clay $(1000 \mathrm{~g})$ was added to $1200 \mathrm{~cm}^{3}$ of water, and this was repeated accordingly. The soil sample was mixed in the mixer for approximately five minutes. Vaseline was applied to the Oedometer ring to reduce friction between the soil sample and the ring. The soil mixture was then poured into the Oedometer apparatus. Due to the variability of the sample scale used, a pre-consolidation pressure of $27 \mathrm{kPa}$ was applied for four hours to allow for excess water to be dissipated. This was done by allowing the soil to drain both ways i.e. from the top and bottom. After four hours, the apparatus was dismantled, and the soil trimmed to the required height. The initial moisture contents were obtained from the trimmings. Before the 
consolidation test began, equilibrium was attained at each loading, which was indicated by the nearly constant reading of the dial gauge. In addition to using Vaseline to reduce friction, friction was further evaluated using the formula derived by Sivrikaya and Togrol (2006). It was noted that at a pressure less than $150 \mathrm{kPa}$, there is no significance difference in frictional stress. The observation was at all sample scales except at $\mathrm{D} / \mathrm{H} 4,5$ and 6.5 , with $\mathrm{D} / \mathrm{H}=4$ being greatly influenced (Rosine and Sabbagh, 2015). The test was ran over a period of 24 hours at load applied in double increments under double drainage condition. Data were obtained using a computerised system connected to each Oedometer test with an accuracy of $\pm 0.1 \%$. The system read data from six channels simultaneously.

\subsection{Scale range}

Oedometer tests were used with three different sample diameters ranging from $100 \mathrm{~mm}$ to 250mm according to the following scenarios (also illustrated in Table 1):

- Height scale (HS): this discusses a state where various thicknesses are used but the diameter of the soil sample is kept constant. Five different heights were used, namely; $23 \mathrm{~mm}, 30 \mathrm{~mm}$, $80 \mathrm{~mm}, 130 \mathrm{~mm}$ and $200 \mathrm{~mm}$.

- Diameter scale (DS): This refers to a situation where the diameter of the sample varies while the soil thickness is kept constant.

At each scale, the initial moisture content and void ratio were calculated. The properties of the

soils used (Table 2) were obtained as per the standard methods: American Standard D2216 (ASTM 2010), British Standard BS1377: part 2 (BS 1990) and American Standard D854 (ASTM 2010), American Standard D4318 (ASTM 2010), and American Standard D2571 (ASTM 2001). 

Table 1: Parameters for the finite element model

\begin{tabular}{|c|c|c|c|c|c|c|c|c|c|c|c|c|c|}
\hline 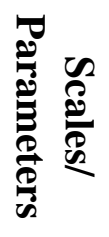 & 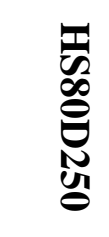 & 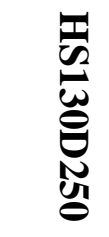 & 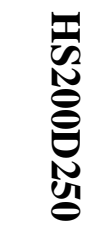 & 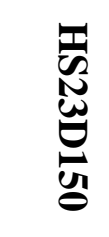 & 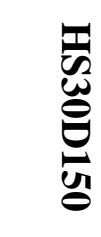 & 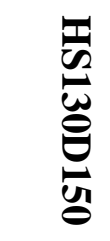 & 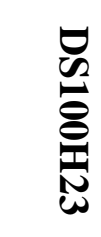 & 导 & 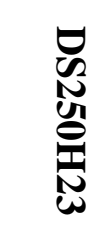 & 莺 & 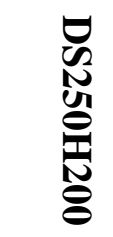 & 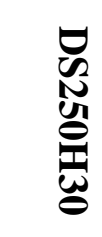 & 导 \\
\hline$\gamma_{\text {sat }}$ & 17.0 & 15.4 & 14.4 & 15.7 & 15.9 & 15.0 & 17.3 & 15.7 & 15.8 & 14.2 & 14.4 & 15.4 & 15.0 \\
\hline $\mathbf{e}_{\mathbf{i}}$ & 1.2 & 1.9 & 2.0 & 1.6 & 1.5 & 1.9 & 2.0 & 1.6 & 1.6 & 2.5 & 2.0 & 1.9 & 1.9 \\
\hline $\mathbf{W}_{\mathbf{i}}$ & 55 & 55 & 55 & 59 & 60 & 74 & 67.5 & 67.5 & 67.5 & 91 & 55 & 55 & 74 \\
\hline $\mathbf{W a}$ & & 55 & & & 64.5 & & & 67.5 & & & & & \\
\hline
\end{tabular}

Where; $\mathrm{w}_{\mathrm{i}}=$ initial moisture content $(\%), \mathrm{w}_{\mathrm{a}}=$ average initial moisture content $(\%), \mathrm{e}_{\mathrm{i}}=$ initial void ratio, $\gamma_{\text {sat }}=$ saturated unit weight $\left(\mathrm{kN} / \mathrm{m}^{3}\right)$ and $\mathrm{E}=$ Young's modulus (assumed $1000 \mathrm{kN} / \mathrm{m}^{2}$ ). 
Table 2: Soil Properties summary

\begin{tabular}{|l|l|l|l|l|l|l|l|}
\hline & $\mathbf{L L}$ & $\mathbf{P L}$ & $\mathbf{P I}$ & $\mathbf{G}_{\mathbf{s}}$ & $\mathbf{D}_{\mathbf{1 0}}$ & $\mathbf{C}_{\mathbf{u}}$ & \multicolumn{2}{|l|}{ Mineralogy } \\
\hline Kaolin clay & $63 \%$ & $32.4 \%$ & $30.6 \%$ & 2.6 & 0.28 & $0.28-12$ & Kaolinite and \\
\hline
\end{tabular}

Where; $\mathrm{LL}=$ liquid limit $(\%), \mathrm{PL}=$ plastic limit $(\%), \mathrm{G}_{\mathrm{s}}=$ specific gravity, $\mathrm{C}_{\mathrm{u}}=$ undrained shear strength $(\mathrm{kPa})$ and $\mathrm{D}_{10}=$ is the average particle size $(\mathrm{mm})$.

\subsection{Experimental Results}

Figure 1a and $\mathrm{b}$ shows the general trend in void ratio vs stress relationship where the void ratio decreases with an increase in stress. At a constant soil thickness of $23 \mathrm{~mm}$ (Figure 1a), as the diameter of the soil increases, the initial void ratio decreases, due to the rearrangement of the soil particles with sample scale. However, at a constant soil thickness of $200 \mathrm{~mm}$, as the diameter increases there is an increase in initial void ratio, whereas, at constant soil diameter of $250 \mathrm{~mm}$, as the soil height increases, the initial void ratio increases as well. At diameter $150 \mathrm{~mm}$, a fluctuation in the initial void ratio is observed as the soil thickness increases (Figure 1b). The value of $c_{v}$ obtained was correlated with the various sample diameter and height scale with a positive correlation factor of 0.027 and 0.641 respectively. The correlation factor shows that sample diameter scale is more dependent on $\mathrm{c}_{\mathrm{v}}$ as compare to height scale. As the diameter increases, there is a reduction in the rate of consolidation only at soil thickness of $23 \mathrm{~mm}$, whereas at soil thickness between $80 \mathrm{~mm}$ and $130 \mathrm{~mm}$, there is a fluctuation in the rate of consolidation as the load increases (refer to Figure 1c). Pattern shown in Figure 1c is similar with sample height scale. 

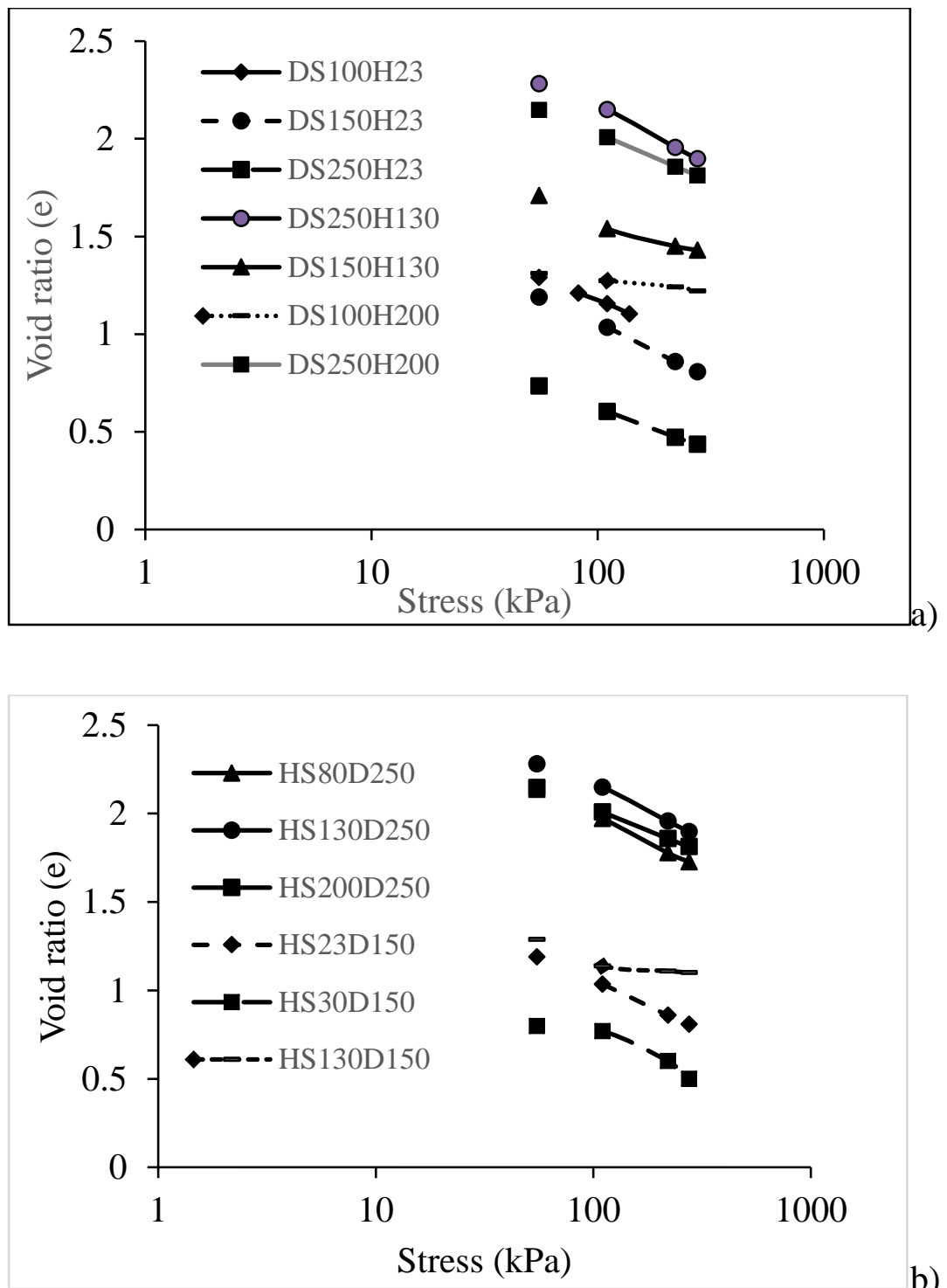

b)

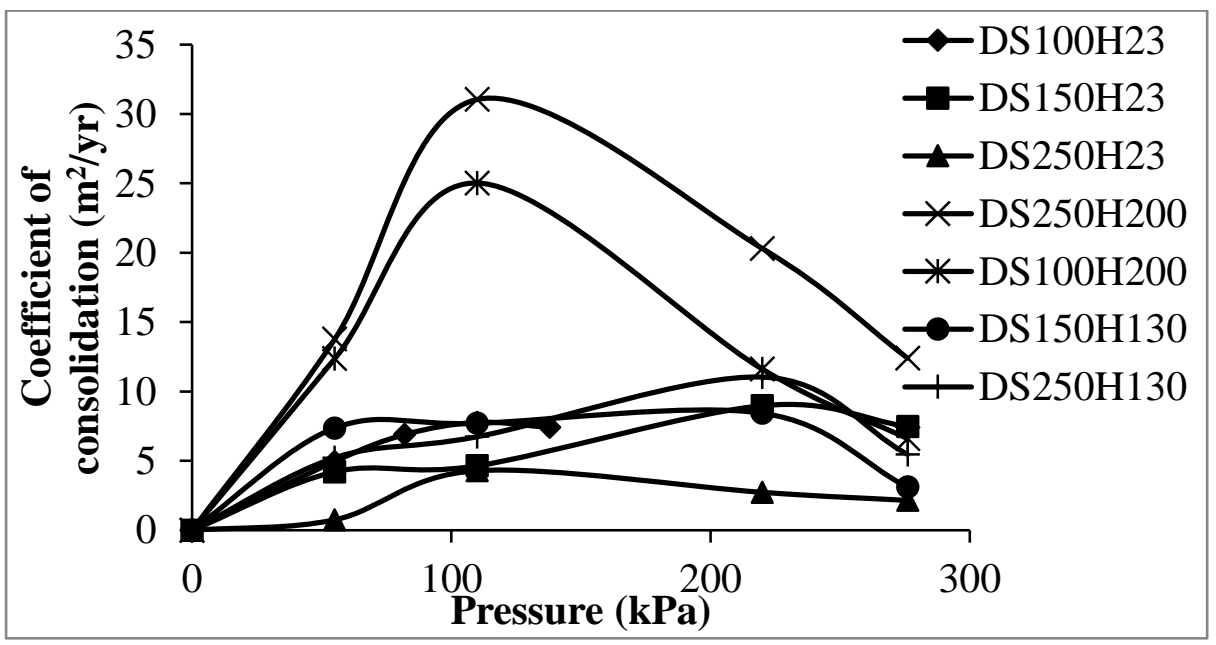

c)

Figure 1: Effect of sample scale on the compressibility parameters of fine-grained soils (Rosine, 2015) 


\section{Finite element analysis}

Finite element (FE) analyses were performed to investigate the behaviour of fine-grained soils at various scales. The Kaolin clay soil was modelled using MC model in PLAXIS. It is vital to generate the finite element model (FEM) that will reasonably capture the performance of soil behaviour under one-dimensional consolidation. The following steps and assumptions were followed during the input process in PLAXIS:

1. Finite element model layout: A scale model is drawn on PLAXIS using an axisymmetric model with 15 nodes for better accuracy. The model includes one clay layer with thickness varying depending on the scale used.

2. One case scenario was considered where both top and bottom of the soil matrix are permeable while the sides are impermeable boundary condition. This allowed the flow to be vertical only. The FEM model is shown in Figure 2 where $\mathrm{q}$ is the applied external load.

3. Sensitivity study was conducted prior to mesh generation. The mesh dependency on sample scale was studied using two meshes: coarse and fine mesh, for each mesh, a 15noded axisymmetric model was used. It was envisaged by the authors that due to the simplicity of the current study model, the meshing type would not be of great significance to the soil behaviour. Hence, coarse mesh was selected due to the quick calculation time of the output results.

4. Soil parameters: Appropriate selection was taken from laboratory tests and some parameters were estimated as shown in Table 1.

5. Construction stages: the construction stages are selected according to the consolidation process and model type uses. The solution was completed using undrained conditions. The calculated running time duration per stages is 24 hours. The initial condition occurs where zero initial stress is generated by using the K0 procedure where $\Sigma$ Mweight (total 
multiplier of the material weight) equals to zero. The distributed load is activated in a separate phase (phase 1) where the calculation phase is plastic analysis. The reset displacement to zero and update mesh is selected.

6. During the analysis, the coefficient of permeability was assumed to be constant. The estimated coefficient of permeability $\left(\mathrm{k}_{\mathrm{e}}\right)$ employed in PLAXIS had a value of $5.5 \times 10^{-}$ ${ }^{7} \mathrm{~m} / \mathrm{s}$. The $\mathrm{k}_{\mathrm{e}}$ value in PLAXIS was obtained using the inputted initial void ratio.

\subsection{Verification of the Finite element model}

The finite element model was first calibrated by comparing the result of the model with the laboratory model. For representation purposes, HS130D150 was used for the calibration. As the excess pore pressure increases, there is a decrease in a volumetric strain which was observed using the FEM. This observation is depicted in Figure 2. This shows that the FEM can simulate the stress-strain behaviour of the soil with good accuracy with the maximum difference of $0.2 \%$. This was observed with the remaining sample scale. Thus, the data obtained using PLAXIS closely matched the experimental data.
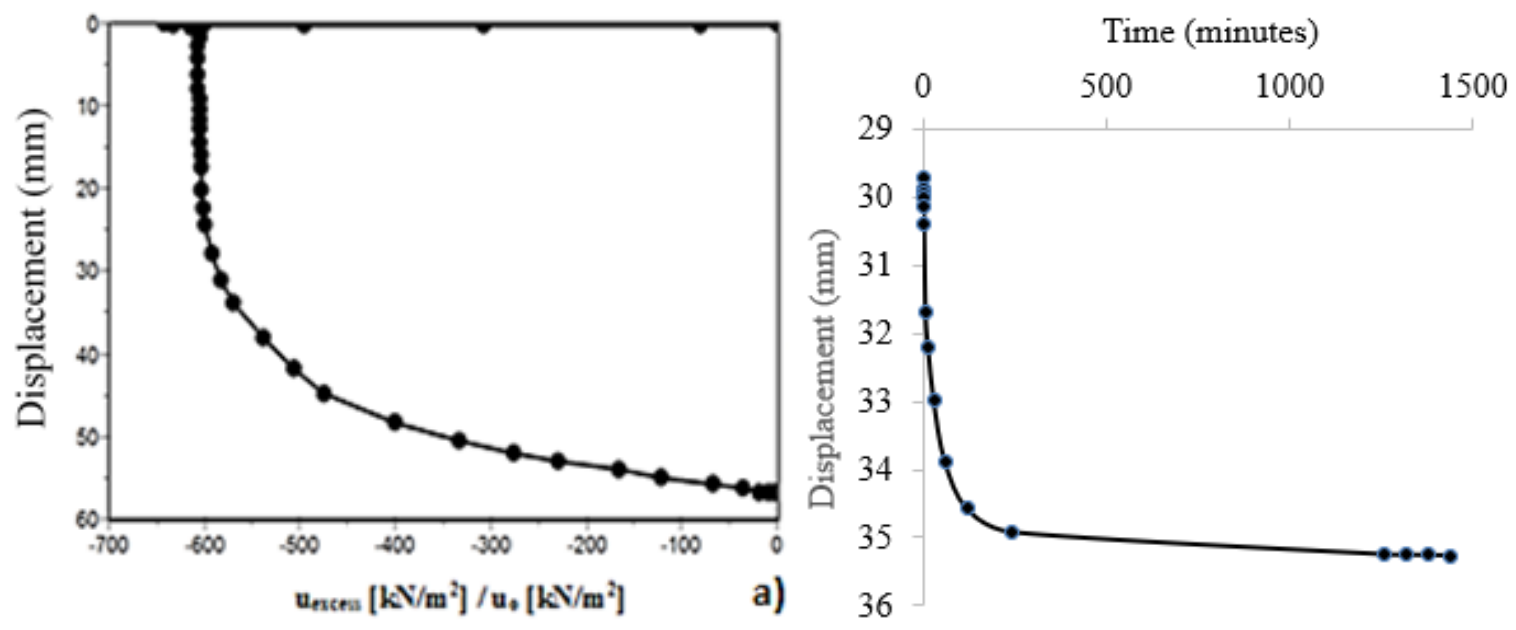

Figure 2. Comparison between experimental and numerical model at $110 \mathrm{kPa}$ for HS130D150; a) normalised finite element model and b) experimental model. Where; $u_{\text {excess }}$ is the excess pore pressure $(\mathrm{kPa})$ and $\mathrm{u}_{0}$ is initial pore pressure ( $\left.\mathrm{kPa}\right)$ (Rosine, 2015) 


\section{2. $\quad$ Finite element solution}

The finite element solution was conducted considering zero initial excess pore water pressure and an external load applied to the surface of the soil skeleton. Hence, from the FEM model, the dissipation of the excess pore water pressure was observed, which confirms the theoretical statement where the excess pore pressure is evenly distributed and is equal to the external load. Figure 3 shows the FEM model mesh (coarse) with nodes and stress points used for plotting curves. The remaining scales follow the same pattern as that presented in figure $3(\mathrm{a} \& \mathrm{~b})$. The external load varies from $0 \mathrm{kPa}$ to $276 \mathrm{kPa}$ to reflect load used in the laboratory. The model obtained using load $55-110 \mathrm{kPa}$ will be presented for illustration purposes in this paper.
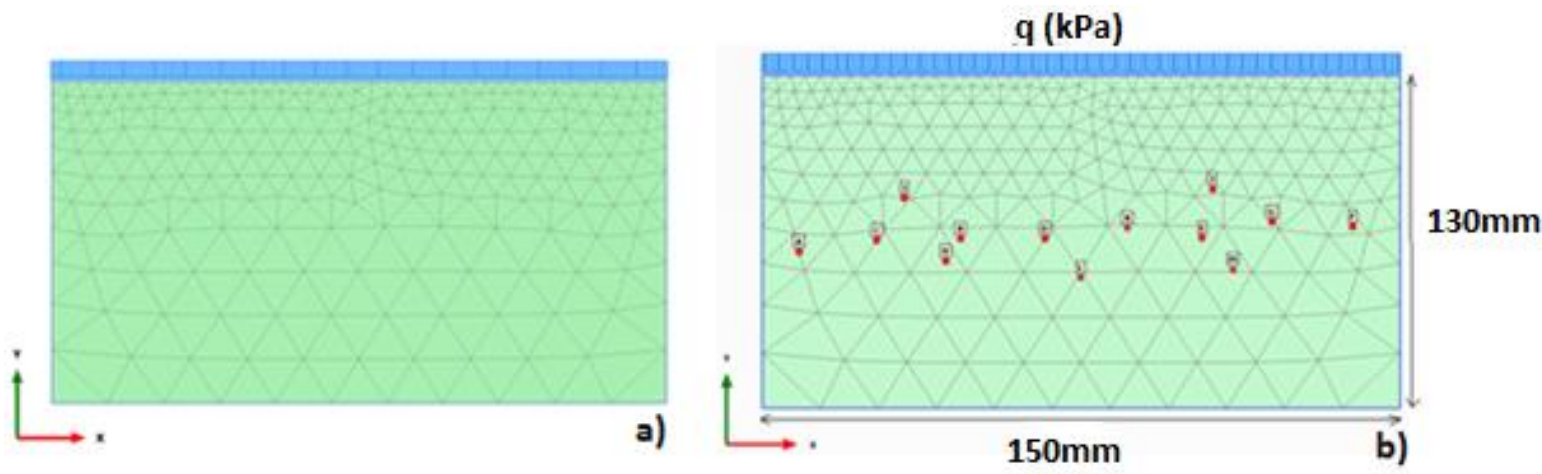

Figure 3. Axisymmetric FEM model: a) coarse mesh and b) mesh with node points used to plot graph

\subsection{Excess pore pressure distribution}

Figure 4 shows the difference in excess pore pressure at mid-depth in the soil matrix, it shows that the excess pore pressure is influenced by sample height scale which was also observed by previous researchers. The trends in behaviour between each scale are more or less the same for DS and HS. HS130D150 is 3\% and 43\% away from HS80D250 and HS80D150 respectively and the remaining HS. As the load is applied, greater settlement takes place with excess pore pressure been dissipated. As water is dissipated under double 
drainage conditions, the excess pore water pressure occurs at the centre of the soil stratum (Figure 5).

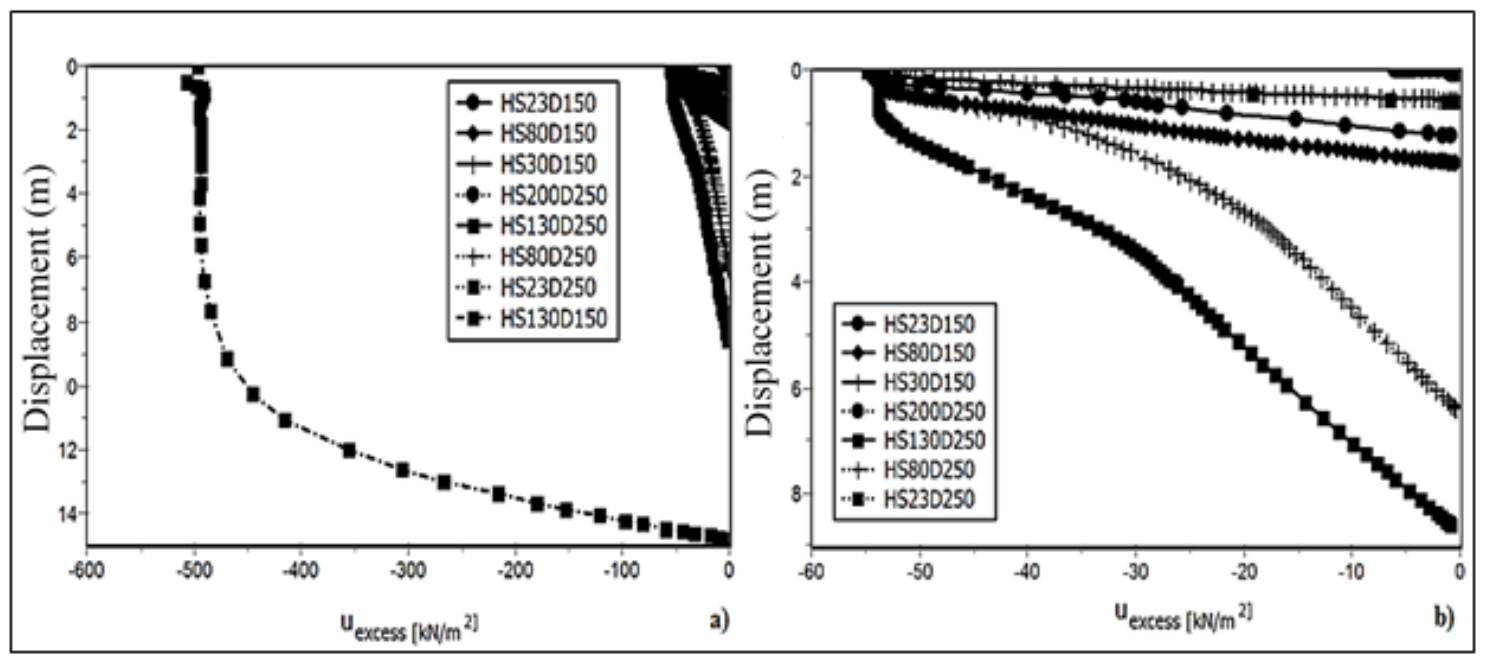

Figure 4. Variation of excess pore pressure using external load $55 \mathrm{kPa}$

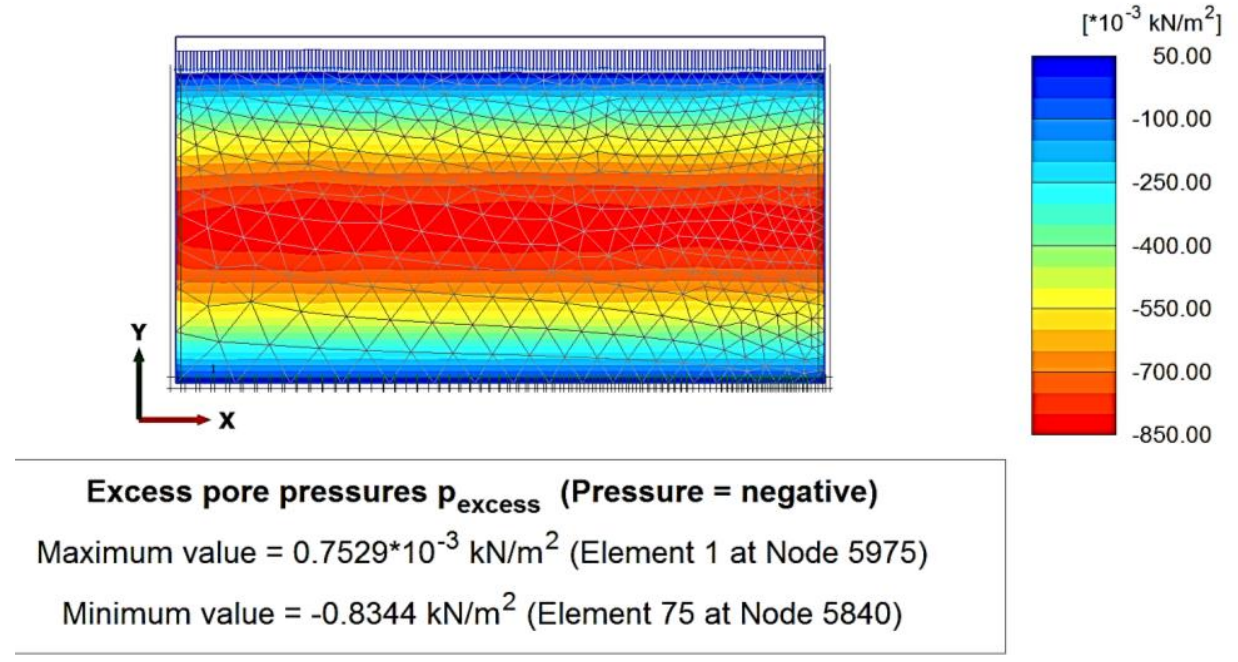

Figure 5. Excess pore pressure distribution at HS80D150

\section{New estimated two-dimensional analysis model}

Further analysis was conducted under the DS in PLAXIS. Head (1992) presented different drainage scenario that can be taken into consideration during consolidation analysis (Figure 6a). Healy and Ramanjaneya (1970) investigation under DS used radial drainage with the implementation of sand drain and found that there is no significant impact of DS on $\mathrm{c}_{\mathrm{v}}$. Healy's findings cannot be directly compared with the outcome in 
this study due to: different soil sample used and different drainage condition. For further validation purposes of the DS outcome, the experimental data was model within PLAXIS under different drainage conditions. A schematic drawing of the drainage condition is shown in Figure $6 b$.

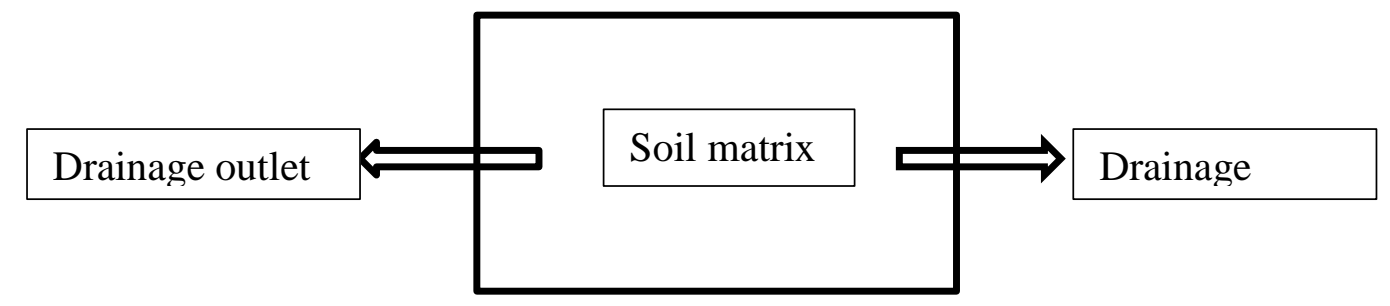

a)

b)

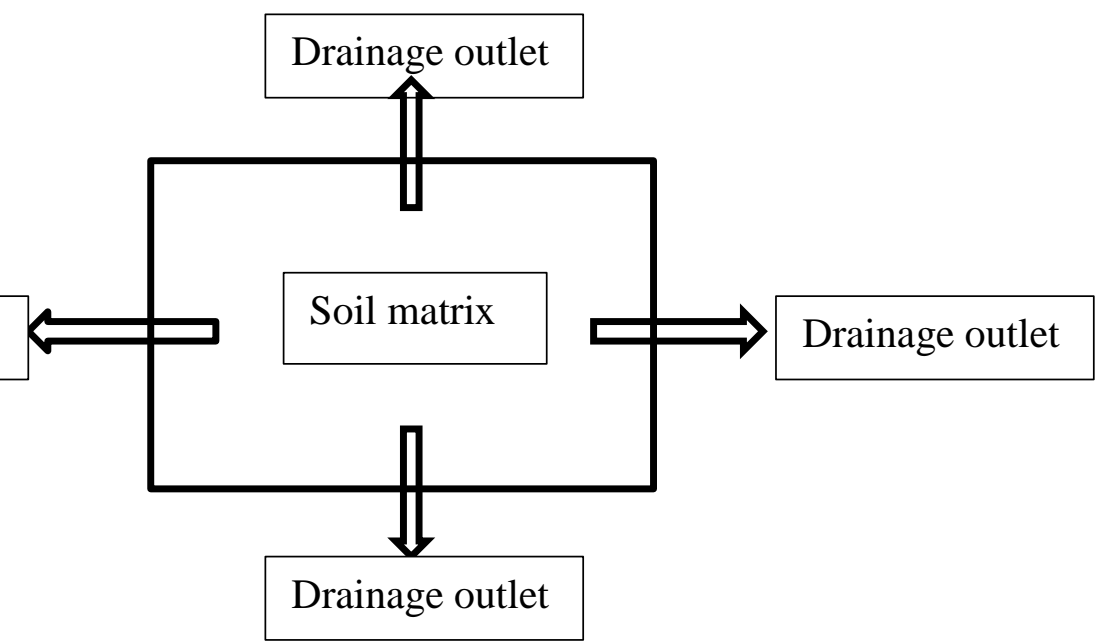

Figure 6. Schematic drainage representation of the FEM for DS; a) case 1 where soil is allowed to drain sideways (horizontal drainage) and b) case 2 current study new model where the soil is allowed to drain in all directions

Both the combined vertical and horizontal drainage has been previously studied using sand drains. Theoretically, Figure 6a is designed with a central sand drain where the soil can drain horizontally and vertically through the sand drain (Head,1998). However, the current study adopts a different approach in Figure 6a and b without the use of a sand drain. Under case 1 (Figures 7 and 8), the soil behaviour had a 50\% difference with vertical drainage. Theoretically, the rate of consolidation is rapid in Figure 6b compared to Figure 6a. When the soil diameter increases from $150 \mathrm{~mm}$ to $250 \mathrm{~mm}$, there is a 
confirmed relationship in the excess pore pressure between case 1, case 2 and vertical drainage (Figure 8i). However, DS150H130 shows a marginal affiliation between the drainage scenarios and there is a 5\% difference between case 1 and 2 at DS150H80 (Figures $7 \mathrm{a}$ and $8 \mathrm{~h}$ ). The variation in behaviour is due to the variation in the diameger to height $(\mathrm{D} / \mathrm{H})$ ratio where $\mathrm{D} / \mathrm{H}$ is less than 2.5 (the recommended value by the American standard), showing inconsistent results. The similarity in drainage scenarios is due to length of drainage and the $\mathrm{D} / \mathrm{H}$ ratio. Case 1 in Figure $7 \mathrm{c}$ calculation phase failed due to soil collapsing before the end of the consolidation stage, and NAN being found. NAN meaning not a number and within PLAXIS is correlate to the soil strength. It was also observed that case 2 and the vertical drainage produced consistent identical excess pore pressures at all sample scales with $\mathrm{D} / \mathrm{H}$ greater than 2 , which could be associated to sample scale and strength of the soil.

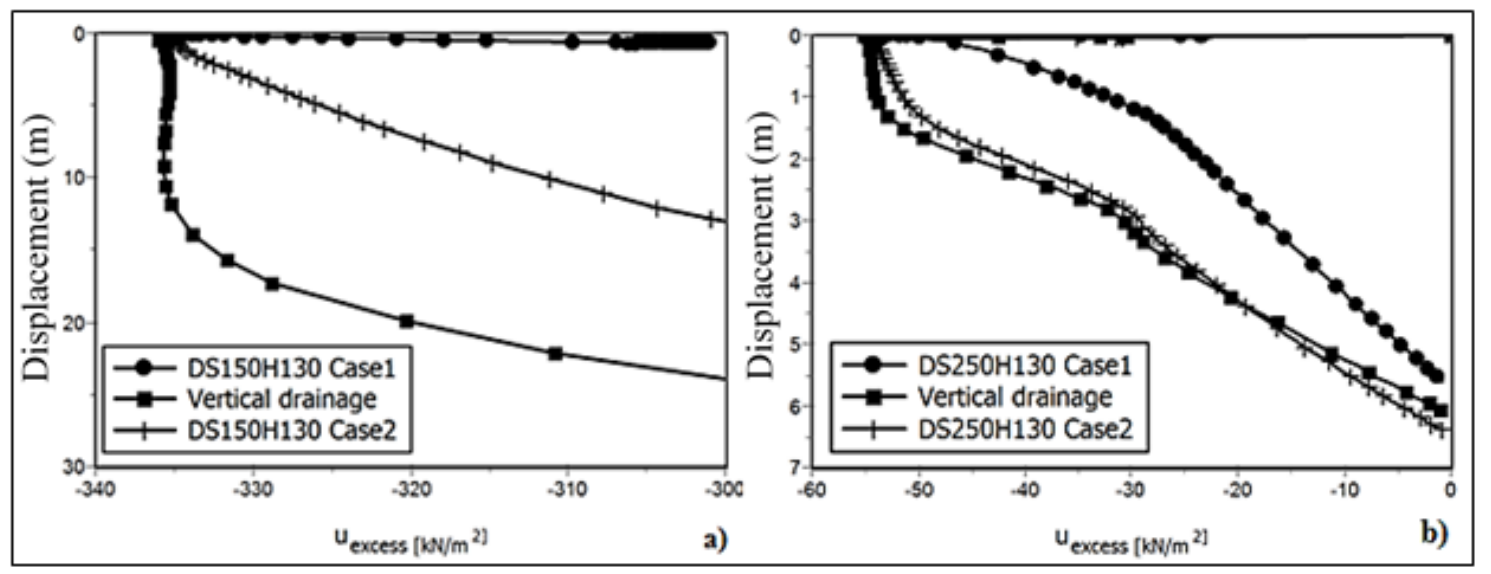

Figure 7: Comparison between vertical, case 1 and case 2 at various sample diameter scales at $55 \mathrm{kPa}$ (Where: case 1 is the horizontal drainage scenario and case 2 is combined vertical and horizontal drainage) (Rosine, 2015) 

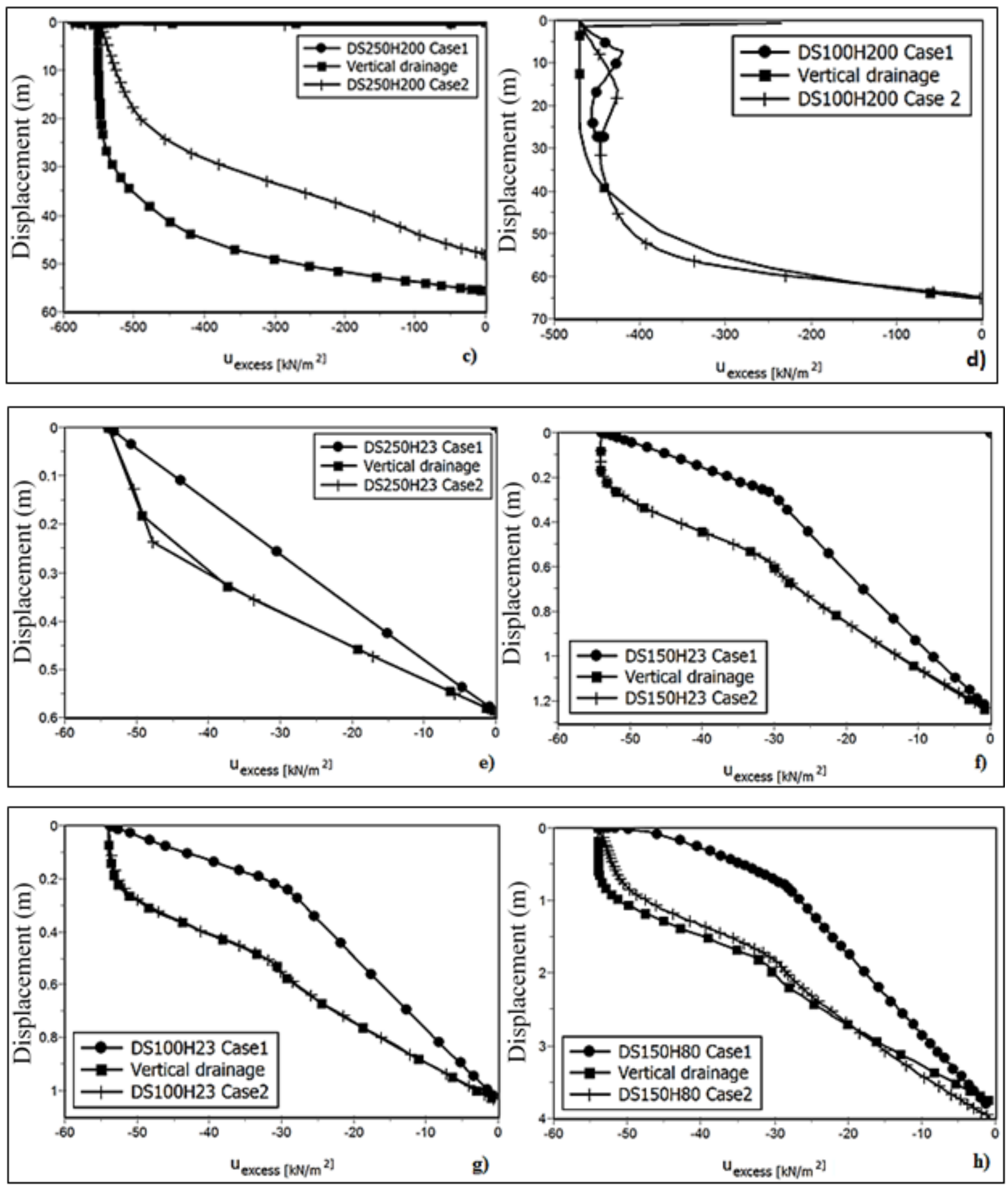

Figure 8: Comparison between vertical, case 1 and case 2 at various sample diameter scales at $55 \mathrm{kPa}$ (Figure 7 continued) (Where: case 1 is the horizontal drainage scenario and case 2 is combined vertical and horizontal drainage) (Rosine, 2015) 


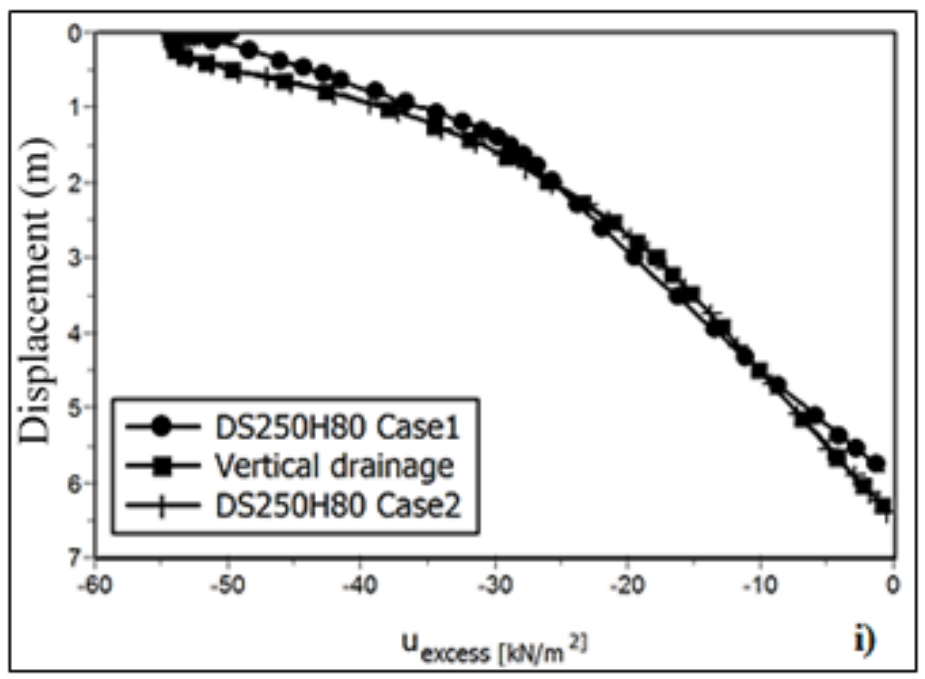

Figure 9: Comparison between vertical, case 1 and case 2 at various sample diameter scales at $55 \mathrm{kPa}$ (Figure $7 \& 8$ continued) (Where: case 1 is the horizontal drainage scenario and case 2 is combined vertical and horizontal drainage) (Rosine, 2015)

Under case 2, $\mathrm{u}_{\text {excess }}$ was more representative for DS250H130 (Figure 7b) as compared to case 1 . This could be due to the loading condition, consolidation time and the ratio of the diameter and height of the soil. It was also observed that, where the flow is allowed horizontally instead of vertically, soil behaviour at DS250H200 (Figure 8c) and DS100H200 (Figure 8d) generates a considerable difference in performance. Thus, where DS is a concerned, soil thickness ranging from $23-130 \mathrm{~mm}$ for soil diameter varying from 100 to $250 \mathrm{~mm}$ produce exact solutions. For consistency, this statement is only valid for case 2. Figures 7 to 9 trends shows that at each DS, the soil behaviour differs at an accuracy of $0.1 \%$ between case 1 and 2 at all scale except at DS250H130.

\section{Conclusion}

A model validation of the effect of scale on the behaviour of kaolin clay was presented with comparison with experimental data and previous work. It was observed that as the initial load is applied to fully saturated soil, large deformation occurs at the soil surface till the mid-depth of the soil profile where less deformation occurs. The experimental data correlates well with the numerical model, therefore validating results. Several scale 
presented such as height and diameter scale has shown to influence soil behaviour greatly particularly at the diameter scale. As the diameter scale increases (from $100 \mathrm{~mm}$ to $250 \mathrm{~mm}$ ) with the soil thickness kept constant and the water flow being vertical, a positive linear increase in excess pore pressure with strain was observed at 150 and $250 \mathrm{~mm}$ middepth. However, under horizontal drainage condition, a negative linear increase in excess pore pressure was observed. This discrepancy could be due to non-uniform load distribution and diameter to height ratio $(\mathrm{D} / \mathrm{H})$ of the soil matrix. This trend was also observed at the remaining scale but at the soil surface. Thus, with a diameter to height $(\mathrm{D} / \mathrm{H})$ ratio greater than $4(\mathrm{DS} 150 \mathrm{H} 23$ and $\mathrm{DS} 250 \mathrm{H} 23)$ acceptable data is obtained. At DS100H200 and DS250H200, there was a steady decrease in strain with time under vertical drainage. The fluctuation in soil behaviour was observed under the DS. The uncertainty of this fluctuation was investigated numerically under horizontal drainage and both vertical and horizontal drainage. A similar outcome was observed but with negative excess pore pressure. The findings contradict Healy's findings on Varved clay where only two diameters were used such as $97 \mathrm{~mm}$ and $147 \mathrm{~mm}$ under radial consolidation. Hence, it can be concluded that DS has a great influence on saturated kaolin clay behaviour as compared to Varved clay.

\section{REFERENCES}

Aissa C. \& Abdeldjalil Z. 2013. Modelisation numerique et analyse de comportment d'un ecran de soutenement autostable. $31^{\text {eme }}$ rencontres de L'AUGC, E.N.S., Cachan, Pp.1-13

American Society for Testing and Materials, 'D2216', Standard test methods for laboratory determination of water (moisture) content of soil and rock by mass, 2010 
American Society for Testing and Materials, 'D854', Standard test methods for specific gravity of soil solids by water pycnometer, 2010

American Society for Testing and Materials 'D2571', Standard test method for field vane shear test in cohesive soils, 2001

American Society for Testing and Materials, 'D4318', Standard test method for liquid limit, Plastic limit and plasticity index of soils, 2010

Berry P.L. \& Reid D., An Introduction to Soil Mechanics, McGraw-Hill, 1987, 100-137

British Standard Institution, BS 1377: PART 2: 1990, Methods of tests of soils for civil engineering purposes - Classification Tests, 1990

Head K.H., Manual of Soil Laboratory Testing. Effective stress tests, $2^{\text {nd }}$ edition, 1992, 3 , 340

Head K.H. 1998. Manual of Soil Laboratory Testing. Effective stress tests, $2^{\text {nd }}$ edition, Vol.3, Pp. 340 - 367

Healy K.A. \& Ramanjaneya G.S., Consolidation characteristic of a Varved Clay, Report, 1970, Department of Civil Engineering, University of Connecticut

Khan P.A., Madhav M.R. \& Reddy E.S., Comparative study of linear and non-linear theories one-dimensional consolidation of thick clay layers, Lowland Technology International, 2012, 14(1), 19-30

Lenk P., Modelling of Primary Consolidation, Slovak Journal of Civil Engineering, 2009, 26-37

Ortega A.G., Variability of the coefficient of consolidation of the Mexico City clayey sediments on Spatial and Timescales, In: Bulletin of the International Association of Engineering Geology, 1996, 54(1), 125-135 
PLAXIS [Software Program], Reference Manual, 2012, P.O. Box 572, 2600 AN Delft, the Netherlands

POPA H. \& BATALI L. 2010. Using finite element method in geotechnical design. Soil Constitutive laws and calibration of the parameters. Retaining wall case study. WSEAS Transactions on Applied and Theoretical Mechanics, 5(3), Pp.177-186

Rosine T.N. \& Sabbagh T.T., The impact of the diameter to height ratio on the compressibility parameters of saturated fine-grained soils, International Journal of Research and Engineering Technology, 2015, 4(5), 8-19

Rosine T.N., The impact of sample scale on the compressibility parameters of saturated fine-grained soils, $P h D$ thesis, Department of Civil engineering, University of Salford, 2015, 86-91

Sivrikaya O. \& Togrol E., Measurement of side Friction between specimen and consolidation Ring with Newly Designed Oedometer Cell. Geotechnical Testing Journal, 2006, 29 (1), 87-94

Wong W.K.J. 2013. Comparison of drainage line elements in PLAXIS 2D and 3D applied in consolidating marine clay deposits. Soft soil engineering international conference, Kuching, Sarawak, Malaysia, Pp.1-8

Yin J.H. \& Graham J., Elastic Visco-Plastic modelling of one-dimensional consolidation, Geo-technique, 1996, 46(46), 515-527 